10 Cope, C. L., Adrenal Steroids and Disease, Second ed.(Pitman Medical, London, 1972).

Niederer, W., Richardson, B. P., and Donatsch, P., Expl Eye Res., 20, 329-340 (1975)

2 Johnson, D. W., Am. Zool, 13, 799-818(1973)

13 Doneen, B. A., and Bern, H. A., J. exp. Zool., 187, 173-179 (1974).

\section{Action of progesterone on preoptic thermosensitive neurones}

FEMALE body temperature rises by about $0.5^{\circ} \mathrm{C}$ at or near ovulation and remains elevated during the luteal phase of the menstrual cycle. Sustained elevation of basal body temperature is observed also during early pregnancy. These effects have been attributed to progesterone, but little is known about the mechanisms involved ${ }^{1}$. We have now found that the hormone affects the activity of the thermosensitive neurones in the preoptic area of the brain.

These neurones change their discharge frequency in response to changes in local brain temperature: that of warm-sensitive neurones increases with a rise in temperature ${ }^{2-3}$, while that of cold-sensitive neurones increases with a fall in temperature ${ }^{4}$. Intravenous pyrogen in anaesthetised animals (cat and rabbit) decreases the activity of warm-sensitive neurones and increases that of cold-sensitive neurones ${ }^{5-8}$.

Our investigation followed preliminary studies of 23 unanaesthetised female rabbits, injected intravenously with progesterone (more than $5 \mathrm{mg} \mathrm{kg}^{-1}$ ). There was a rise in rectal temperature of $0.6{ }^{\circ} \mathrm{C}$, with the highest elevation in core temperature $2 \mathrm{~h}$ after injection. Progesterone was dissolved in propylene glycol, but the solvent alone did not cause temperature to rise. We have therefore investigated the effect of systemic administration of progesterone on the thermosensitive neurones.
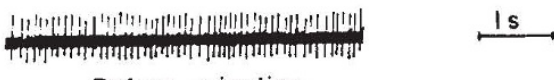

Before injection

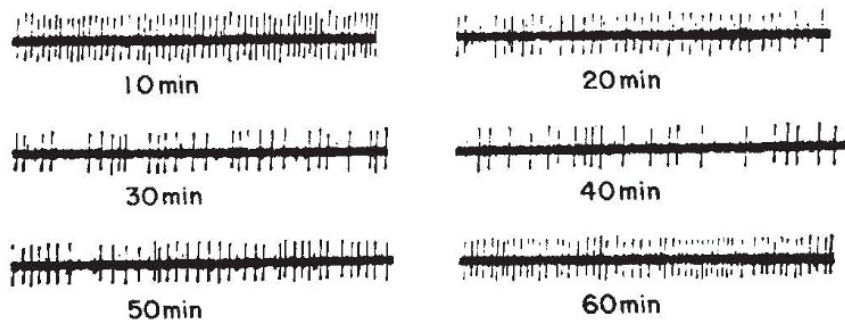

Fig. 1 Discharges of the preoptic warm-sensitive neurone in response to intravenous administration of progesterone in the female rabbit.

Thirty-four female rabbits $(2.5-4.0 \mathrm{~kg})$ were anaesthetised with urethane $\left(\mathrm{g} \mathrm{kg}^{-1}\right)$, tracheotomised and mounted on a stereotaxic apparatus. (Details of the method have been described before ${ }^{3}$.) A thermode was implanted in the preoptic area, $1.5 \mathrm{~mm}$ lateral to the midline, and brain temperature was measured by a thermocouple placed in the frontal plane, $3.0 \mathrm{~mm}$ from the thermode. Impulses of single neurones were recorded on tape and impulses per second were counted with a data processing computer. A small amount of iron was then deposited electrolytically at the tip of the electrode for histological localisation. A neurone with a regular rate of firing was identified as warm-sensitive, cold-sensitive or temperatureinsensitive by its responses to local warming and cooling. The effect of progesterone was observed on twenty warm-sensitive, seven cold-sensitive and five insensitive neurones. Progesterone was dissolved in $50 \%$ propylene glycol $\left(5 \mathrm{mg} \mathrm{ml}^{-1}\right)$. When the thermal response of a neurone had been observed, the brain temperature was kept at $37.5^{\circ} \mathrm{C}$ and progesterone $(10 \mathrm{mg}$ in $2 \mathrm{ml}$ ) was injected intravenously. In a typical warm-sensitive neurone (Fig. 1), the average rate of firing before injection was 11.2 impulses s $^{-1}$. After a latency of about $20 \mathrm{~min}$, this decreased to 7.7 at $24 \mathrm{~min}$, to 6.6 at $40 \mathrm{~min}$ and returned to 10.0 at $60 \mathrm{~min}$. Of the 20 warm-sensitive neurones tested, 15 decreased their firing rate by $38-70 \%$ after administration of progesterone. The thermal responses of these 15 neurones had not changed when observed $60 \mathrm{~min}$ after administration, with the exception of one neurone which showed a decreased thermosensitivity. The rate of firing of five warm-sensitive neurones was unchanged for $2 \mathrm{~h}$ after intramuscular administration of progesterone.

In seven cold-sensitive neurones the rate of firing increased after administration of progesterone given intramuscularly in three cases and intravenously in the other two. In one of these neurones, the rate of firing increased from 6.4 to 12.0 impulses $\mathrm{s}^{-1} 6 \mathrm{~min}$ after injection. Five thermally-insensitive neurones were not affected by progesterone and two warm-sensitive neurones were not affected by propylene glycol.

Plasma concentration of progesterone rises quickly after intravenous administration and returns to a control level in about $1 \mathrm{~h}$ (refs 9 and 10). This may explain the short duration of action of progesterone that we observed. We do not know whether the thermosensitive neurones tested in this study are true thermoreceptors or interneurones transmitting temperature signals in a complex neural network of temperature regulation. Nor are we certain whether the neuronal effects which we observed were caused by progesterone per se or by its metabolites. Furthermore, the quantitative relationship between oestrogen and progesterone in the luteal phase is complex and oestrogenic hormones are known to cause a slight decrease in body temperature ${ }^{11-12}$.

It seems likely, however, that the decreased activity of warmsensitive neurones and the increased activity of cold-sensitive neurones in the preoptic area result in an upward shift of the 'set point' of body temperature, as with the effects of pyrogen. The rise of basal body temperature in the luteal phase seems to be related, at least in part, to the direct or indirect action of progesterone on preoptic thermosensitive neurones.

TERUo NaKaYama MASATOSHI SUZUKI

Department of Physiology, Osaka University, School of Medicine, Kita-ku, Osaka 530

\section{NAOTAKA ISHIZUKA}

Department of Gynecology and Obstetrics, Nagoya University, School of Medicine, Showa-ku, Nagoya 466 Japan

Received August 4; accepted September 12, 1975.

Kappas, A., and Palmer, R. H., Pharmac. Rev., 15, 123-167 (1963). Nakayama, T., Eisenman, J. S., and Hardy, J. D., Science, 134, 560-561 (1961) Nakayama, T., Hammel, H. T., Hardy, J. D., and Ëisenman, J. S., Am. J. Physiol., 204, 1122-1 126 (1963).

204, 1122-1126(1963). F., and Sutherland, K., J. Physiol., Lond., 175, 242-253 (1964).

Cabanac, M., Stolwijk, J. A. J., and Hardy, J. D., J. appl. Physiol., 24, 645-652 (1968).

Wit, A., and Wang, S. C., Am. J. Physiol., 215, 1160-1169 (1968)

Eisenman, J. S., Am. J. Physiol., 216, 330-334 (1969).

Nakayama, T., and Hori, T., J. appl. Physiol., 34, 351-355 (1973).

Zarrow, M. X., Shoger, R. L,, and Lazo-Wasem, E. A., J. clin. Endocr. Metab. $14,645-652$ (1954)

10 Ishizuka, N., J. Jap. Obstet. Gynec. Soc., 9, 907-925 (1957).

11 Buxton, C. L., and Atkinson, W. B., J. clin. Endoc. Metab., 8, 544-549 (1948).

12 Israel, S. L., and Schneller, O., Fert. Steril., 1, 53-64 (1950).

\section{Excitation of phasically firing supraoptic neurones during vasopressin release}

THE neurohypophysial hormones vasopressin and oxytocin are synthesised within separate neurones of the hypothalamic supraoptic and paraventricular nuclei ${ }^{1}$ and each hormone can be liberated independently. Haemorrhage ${ }^{2}$ and bilateral 